\title{
Uso de dilatador temporário em papilas mamárias de vacas, submetidas a lesões experimentais
}

[Use of temporary dilatator in cow mammary papilla submitted to experimental lesions]

\author{
V.A. Gheller ${ }^{1}$, C.A.A. Valadão $^{2}$, C. Malm ${ }^{1}$, H.P. Oliveira ${ }^{1}$, C.M.F. Rezende ${ }^{1}$, E.G. Melo ${ }^{1}$ \\ ${ }^{1}$ Escola de Veterinária - UFMG \\ Caixa Postal 567 \\ 30123-970 - Belo Horizonte, MG \\ ${ }^{2}$ Faculdade de Ciências Agrárias e Veterinárias - UNESP - Jaboticabal, SP
}

\begin{abstract}
RESUMO
Trinta e duas papilas mamárias de vacas da raça Holandesa, em período seco, foram submetidas a telotomia lateral que produziu defeito linear na mucosa da parte papilar do seio lactífero (PPSL). Houve excisão de um retângulo de mucosa de tamanho padronizado que provocou um defeito retangular na mucosa do PPSL, oposto à telotomia. Todas as telotomias foram suturadas e, aleatoriamente, em 16 delas foram introduzidas sondas de Foley de 2,7mm de diâmetro, formando o grupo de papilas com dilatador. A distensão dos balonetes das sondas de Foley provocou a dilatação da PPSL o que forçou a manutenção das sondas, por sete dias, na papila mamária. As 16 papilas restantes formaram o grupo de papilas sem dilatador. Foram realizadas videoteloscopias antes (dia 0) e após as telotomias (dia 8, após a retirada das sondas de Foley e dia 15). As avaliações morfológica e histológica do processo de cicatrização dos defeitos lineares e retangulares evidenciaram que o uso de dilatador na PPSL auxiliou na orientação cicatricial, mantendo a patência do seio lactífero em um maior número de papilas, quando os dois grupos foram comparados. A dilatação da PPSL interferiu na cicatrização das telotomias, e provocou maior número de alterações no epitélio de revestimento do seio lactífero.
\end{abstract}

Palavras-chave: vaca, papila mamária, teto, dilatador, teloscopia

\begin{abstract}
Thirty two mammary teats of Holstein cows, in the dry period, were submitted to histological examination. Lateral thelostomy was performed in all teats, producing a linear defect on the mucous membrane of the lactiferous sinus (MMLS). The teats were also submitted to a standard rectangular excision on the mucous membrane of MMLS, on the opposite side of thelostomy. All thelostomies were sutured and then the teats were divided in 2 groups. One group received Foleys's catheter of $2.7 \mathrm{~mm}$ in diameter and was designed teat distention group. The 16 remain teats formed the no teat distention group. The Foleys's catheter balloon distention produced MMLS dilatation and also a 7 days maintenance period on the mammary teat. The scar evaluation of the linear and rectangular defects, performed trough morphologic and histological examinations showed that the dilatation on MMLS contributes on the scar orientation, keeping the lactiferous sinus patency in a greater number of teats, when both groups were compared. The MMLS dilatation interferes with telothomies healing, can observe so more alterations on the mucous membrane of lactiferous sinus.
\end{abstract}

Keywords: cow, mammary teat, teat, dilatator, theloscopy

Recebido em 24 de maio de 2007

Aceito em 24 de setembro de 2007

E-mail: valentim@vet.ufmg.br

Apoio: FAPEMIG 


\section{INTRODUÇÃO}

As afecções da glândula mamária são responsáveis pela redução na produção e, conseqüentemente, na lucratividade da exploração leiteira, podendo causar o descarte do animal ou reduzir seu valor final de venda, causando prejuízos ao empreendedor.

Entre as lesões não infecciosas mais freqüentes, as fibroses obstrutivas da papila mamária interferem diretamente no fluxo da extração do leite pela ordenhadeira mecânica e predispõem a glândula mamária a outras afecções (Agger e Hesselholt, 1986).

Com o propósito de resolver casos de fibroses da papila mamária, houve incremento na prática de abordagens cirúrgicas por telotomias laterais, que são eficientes como método de exploração da parte papilar do seio lactífero e proporcionam excelente resolução cicatricial. No entanto, as telotomias laterais apresentam-se insatisfatórias na resolução das obstruções, principalmente porque a retirada da fibrose produz lesão na mucosa do seio lactífero e não permite uma adequada aposição da mucosa por padrões de sutura tradicionais, levando a recidiva de fibrose de forma mais intensa. Tal limitação motivou a busca de algumas alternativas de tratamento cirúrgico que proporcionassem melhor resultado final, como, por exemplo, o implante de mucosa oral e vulvar nas lesões de mucosa no seio lactífero (Bristol, 1988). Outra alternativa de tratamento proposta por Ames e Coy (1984) e Nassef et al. (1988) foi a colocação de tubos de silicone na parte papilar do seio lactífero para manter sua patência, possibilitando a ordenha e manutenção da vaca no rebanho. Essas experiências não apresentaram resultados satisfatórios, e até mesmo foram consideradas desapontadoras por John et al. (1998), quando utilizadas em processos obstrutivos localizados na parte proximal da papila mamária.

Novas tecnologias estão sendo utilizadas para investigação das patologias localizadas na luz do seio lactífero e passíveis de intervenção cirúrgica. A videoteloscopia permite a visualização de estruturas com magnificação de imagens e com mínima agressão tissular. Esta abordagem é promissora e permite avaliar as afecções mamárias que levam a redução do fluxo lácteo durante a ordenha, principalmente nos casos de obstrução da papila mamária.

Este trabalho teve como objetivo investigar, por meio de videoteloscopia e histologia, a evolução dos defeitos lineares e retangulares provocados experimentalmente na mucosa da parte papilar do seio lactífero por telotomia, simulando-se as condições cirúrgicas normalmente utilizadas.

\section{MATERIAL E MÉTODOS}

Foram utilizadas oito vacas da raça Holandesa, preto e branco, em período seco, provenientes de rebanhos submetidos à ordenha mecânica, três vezes ao dia, que tiveram três períodos completos de lactação durante sua vida produtiva. As vacas foram alojadas em piquetes, passaram por um período de adaptação de 10 dias e tiveram uma dieta alimentar à base de silagem de milho, ração farelada (12\% proteína $)^{1}$ e sal mineralizado disponibilizados em cochos coletivos. Estes animais não apresentaram alterações inflamatórias e anatômicas na glândula mamária detectáveis por avaliação clínica e videoteloscópica.

Foram realizadas três videoteloscopias (VT). A primeira, no dia zero (VT-0), proporcionou visualização inicial das papilas mamárias e foi realizada nos seguintes tempos: após contenção da vaca em tronco, procedeu-se à higienização do úbere com água e sabão e anti-sepsia com solução iodo-glicerinada a $2 \%$; procedeu-se à anestesia local com infiltração circular, na base da papila mamária, de 5 a $8 \mathrm{ml}$ de cloridrato de lidocaína a $2 \%^{2}$, sem vasoconstritor. A desinfecção do endoscópio rígido de $2,7 \mathrm{~mm}$ e $30^{\circ}$ foi realizada com glutaraldeído a $2 \%{ }^{3}$. Para permitir a inspeção videoteloscópica da porção papilar do seio lactífero, uma pinça de Doyen colocada na base da papila foi insuflada com ar até obter-se distensão suficiente para a visualização das estruturas internas. Através do ducto papilar introduziu-se o endoscópio, no seio lactífero da papila mamária e observaram-se a aparência da mucosa, a ocorrência de lesões, obstruções e alterações inflamatórias. Em

${ }^{1}$ Itambé - Cooperativa Central dos Produtores Rurais de Minas Gerais - Belo Horizonte, Brasil.

${ }^{2}$ Cristália Produtos Químicos e Farmacêuticos - Itapira, Brasil.

${ }^{3}$ Glutaralster - Áster Produtos Médicos Ltda - Sorocaba, Brasil. 
seguida, retirou-se a pinça de Doyen e visualizou-se a região entre a parte papilar e a parte glandular do seio lactífero. O exame das quatro papilas mamárias foi feito no sentido horário, iniciando-se pela papila anterior esquerda.

Após a VT, as vacas foram submetidas às telotomias laterais. A anti-sepsia da papila mamária foi feita com solução de polivinilpirrolidona a $10 \%{ }^{4}$ e álcool iodado a $2 \%$ e a incisão de pele, subcutâneo e camadas musculares, com bisturi, na porção lateral da papila mamária (Fig. 1). Introduziu-se sonda mamária metálica de $2,7 \mathrm{~mm}$ de diâmetro, no interior da PPSL, através do ducto papilar, para facilitar a incisão da submucosa e mucosa. Após pequena abertura, a incisão foi ampliada para $5 \mathrm{~cm}$ de extensão com o auxílio de tesoura de Metzenbaum. Em seguida à abertura da PPSL, a sonda mamária foi introduzida, na incisão. Através do ducto papilar e com rotação de $180^{\circ}$ sobre seu eixo longitudinal, a sonda foi projetada contra a parede medial da papila produzindo exposição parcial da mucosa medial (Fig. 2). Na seqüência, com o auxílio de um delimitador artesanal constituído de lâminas inseridas em bloco de PVC, delimitando um retângulo de 1,5 por $1,0 \mathrm{~cm}$ (Fig. 3) e tesoura de Metzenbaum, procedeuse à excisão de um retângulo de mucosa, de $1 \mathrm{~cm}$ de largura por $1,5 \mathrm{~cm}$ de comprimento, localizado na transição entre parte papilar e parte glandular do seio lactífero, obtendo-se um defeito retangular na mucosa do PPSL. A sonda mamária foi retirada do ducto papilar e realizou-se a telorrafia com fio de náilon monofilamento 2-0 agulhado, no padrão de colchoeiro e em dois planos de sutura, sendo o primeiro plano na submucosa e o segundo no subcutâneo (Ferreira, 1973). Imediatamente após a telorrafia, aplicou-se em cada papila mamária pomada intramamária indicada para vacas em período seco ${ }^{5}$.

Realizou-se sorteio para obter duas papilas mamárias por vaca nas quais foram introduzidas sondas de Foley $(2,7 \mathrm{~mm}$ de diâmetro). Para a dilatação da PPSL o balonete da sonda foi distendido com $5 \mathrm{ml}$ de solução físiológica estéril. A extremidade livre da sonda de Foley foi suturada externamente na pele do úbere, na base da papila, com fio de náilon monofilamento 2-0 agulhado. A sonda foi mantida por sete dias. Formaram-se dois

\footnotetext{
${ }^{4}$ Asteriodine - Áster Produtos Médicos Ltda - Sorocaba, Brasil.

${ }^{5}$ Orbenin Extra Dry Cow - Laboratórios Pfizer Ltda Guarulhos - SP
}

grupos: o grupo das papilas com dilatador (GCD) e grupo sem o dilatador (GSD).

Diariamente, realizavam-se avaliações da condição clínica geral das vacas, ingestão hídrica e alimentar, locomoção e inspeção geral. As telorrafias eram avaliadas quanto à evolução cicatricial, posicionamento do balonete das sondas de Foley e os efeitos da permanência do dilatador.

Com os VT, executados nos dias 8 (VT-8) e 15 (VT-15), visualizaram-se as áreas dos defeitos lineares e retangulares. Atribuíram-se escores relativos aos seguintes parâmetros: obstrução do lúmen do seio lactífero, cicatrização do defeito linear e invasão de tecido no lúmen do seio lactífero no local do defeito retangular. Os escores, em valores percentuais, relativos à obstrução observada no lúmen do seio lactífero foram: $0=0 \% ; 1=25 \%$; $2=50 \% ; 3=75 \% ; 4=100 \%$ de obstrução luminal.

O defeito linear, provocado na mucosa pela telotomia lateral, foi avaliado pelas VT, com atribuição de escores para as seguintes observações: $0=$ totalmente cicatrizado; $1=$ parcialmente cicatrizado; $2=$ parcialmente cicatrizado com presença de tecido cicatricial invadindo o lúmen da PPSL.

Ao defeito retangular na mucosa do seio lactífero foram atribuídos os seguintes escores: $0=$ sem invasão do lúmen do seio lactífero; $1=$ com invasão do lúmen do seio lactífero; 2= Invasão do seio lactífero com obstrução total do lúmen.

Foram também avaliados: deiscência da síntese das telotomias laterais, mamite clínica, bridas teciduais e insuficiência funcional do ducto papilar. Os escores atribuídos para cada parâmetro foram: $0=$ ausente; $1=$ presente.

As papilas mamárias foram submetidas à avaliação histológica. Foram feitos cortes transversais com $2 \mathrm{~mm}$ de espessura nas porções proximal (ducto papilar) e mediana da parte papilar do seio lactífero, abrangendo a telotomia lateral e a área de excisão de mucosa. Os cortes histológicos foram rotineiramente processados, corados pela técnica hematoxilina/eosina (HE) e examinados, em microscópio óptico. As alterações encontradas, com enfoque especial nas metaplasias epiteliais, cicatrização, presença de queratina no lúmen do ducto papilar e alterações inflamatórias, foram relatadas para correlação com os achados videoteloscópicos e macroscópicos. 
Os dados colhidos nos diferentes procedimentos foram submetidos à análise de variância não paramétrica de Kruskal-Wallis para a comparação dos tempos dentro do mesmo grupo. O teste de Wilcoxon foi utilizado na comparação entre os grupos, dentro de cada tempo. Adotou-se o nível de significância de $5 \%(\mathrm{P} \leq 0,05)$.

As respostas dicotômicas relacionadas como a observação de deiscência da ferida cirúrgica, a insuficiência funcional do ducto papilar, a mamite clínica e a visualização de bridas nas videoteloscopias foram avaliadas pelo teste quiquadrado com correção pelo teste exato de Fischer. Os resultados histológicos foram submetidos a uma análise descritiva e comparativa com os achados macroscópicos e videoteloscópicos.

\section{RESULTADOS E DISCUSSÃO}

Os procedimentos cirúrgicos com instrumentos especiais introduzidos pelo ducto papilar para resolução de afecções obstrutivas da papila mamária, têm acesso cirúrgico limitado e alto risco de hemorragias, quando atingem o anel venoso de Fürstenberg (Nickel et. al, 1981). As afecções da PPSL, operadas com instrumentos cirúrgicos introduzidos pelo ducto papilar, sem visualização, costumam lesar indiscriminadamente a porção integra da mucosa, favorecendo a maior formação de tecido fibroso e, conseqüentemente, maior percentual de obstrução (Hull, 1995). Considerando este aspecto, o presente estudo abordou a PPSL por uma telotomia lateral para promover a ablação parcial de mucosa, simulando a técnica preconizada para exérese de processos granulomatosos do seio lactífero (Ferreira, 1973). Associou-se o implante de dilatador na PPSL, pois, segundo Metzger et al. (1999), os implantes de politetrafluoretileno aplicados na PPSL orientam a cicatrização e mantêm a patência papilar do seio lactífero, evitando-se a recidiva de obstruções que são causadas por extensa remoção de mucosa da PPSL.

Pelas avaliações videoteloscópicas, observou-se que as lesões produzidas cirurgicamente na mucosa da PPSL produziram obstruções do lúmen que evoluíram diferentemente na dependência do uso do dilatador. Notou-se nos dois grupos, que a obstrução ocorreu a partir do $8^{\circ}$ dia (Tab. 1). A análise comparativa entre os dois grupos aponta vantagem para o GCD, pois nos tempos observados, um ( $8^{\circ}$ dia) e oito dias $\left(15^{\circ}\right.$ dia $)$, após a retirada do dilatador os percentuais de obstrução foram menores $(\mathrm{P} \leq 0,05)$ neste grupo (Tab. 1). Na VT, observou-se maior percentual de obstruções no GSD, o qual se manteve constante nas duas avaliações.

Tabela 1. Avaliação videoteloscópica de obstrução na parte papilar do seio lactífero (\%) antes (dia 0) e após (dias 8 e 15) a telotomia lateral e da excisão retangular da mucosa do seio lactífero, com (GCD)ou sem (GSD) a aplicação de dilatadores

\begin{tabular}{clc}
\hline Tempo & \multicolumn{1}{c}{ GCD } & GSD \\
\hline Dia 0 & 0,0a,A $(0 / 16)$ & 0,0a,A (0/16) \\
Dia 8 & 50,0a,AB (8/16) & $93,7 \mathrm{~b}, \mathrm{~B}(15 / 16)$ \\
Dia 15 & 62,5a,B (10/16) & $93,7 \mathrm{~b}, \mathrm{~B}(15 / 16)$ \\
\hline
\end{tabular}

Valores seguidos por letras distintas, maiúsculas na coluna e minúsculas na linha, diferem entre si $(\mathrm{P} \leq 0,05)$.

No GCD, ocorreu um aumento do número de obstruções entre o VT-8 e o VT-15, totalizando 10 papilas com diferentes graus de obstrução. No GSD, observou-se mesmo número (15) de papilas obstruídas, porém com modificação nos graus de obstrução (Tab. 2).

Os defeitos extensos na mucosa, após exérese cirúrgica, favorecem a recidiva das fibroses obstrutivas, principalmente por impedir a aposição das bordas da lesão e, nestes casos, é preconizada a implantação de tubos de silicone na PPSL (Dzuba, 1983; Nassef et al. et al., 1988).

Neste aspecto, no GCD, oito dias após a retirada do dilatador $\left(15^{\circ} \mathrm{dia}\right)$, observou-se, por meio da VT, que outras duas papilas apresentaram obstrução. No GSD, no mesmo período, não houve aumento no número de papilas com obstrução, porém, notou-se agravamento dos processos obstrutivos, encontrando-se duas papilas com $100 \%$ do lúmen obstruído e duas papilas com $75,0 \%$ de obstrução (Fig. 4) em comparação com a avaliação do dia 8. Esses dados demonstram que a obstrução do seio lactífero, a partir de lesões na mucosa da PPSL, é rápida e possui diferentes níveis de gravidade, tendo como conseqüência a redução da produção de leite e o aumento do descarte de vacas em rebanhos leiteiros (Roine, 1975). A vasta irrigação oriunda do tecido conectivo frouxo que une a mucosa do seio lactífero às camadas musculares, favorece a proliferação tecidual que invade a PPSL, em casos de extensa lesão na mucosa da papila mamária (Hull, 1995), havendo aumento das reações teciduais na papila mamária quando submetida à ordenha mecânica (Hamann et al. 1993). 


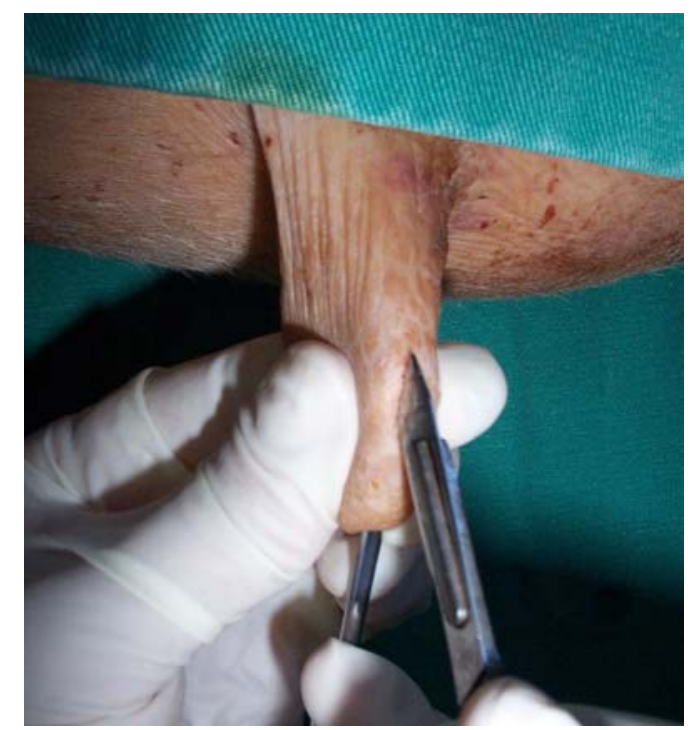

Figura 1. Incisão longitudinal na papila mamária, com sonda metálica no ducto papilar.

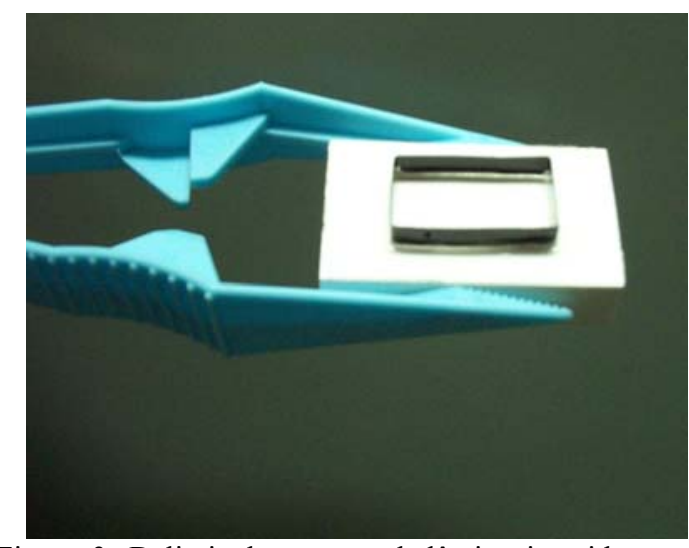

Figura 3. Delimitador artesanal, lâmina inserida em PVC, para demarcar o retângulo de $1,5 \times 1,0 \mathrm{~cm}$.

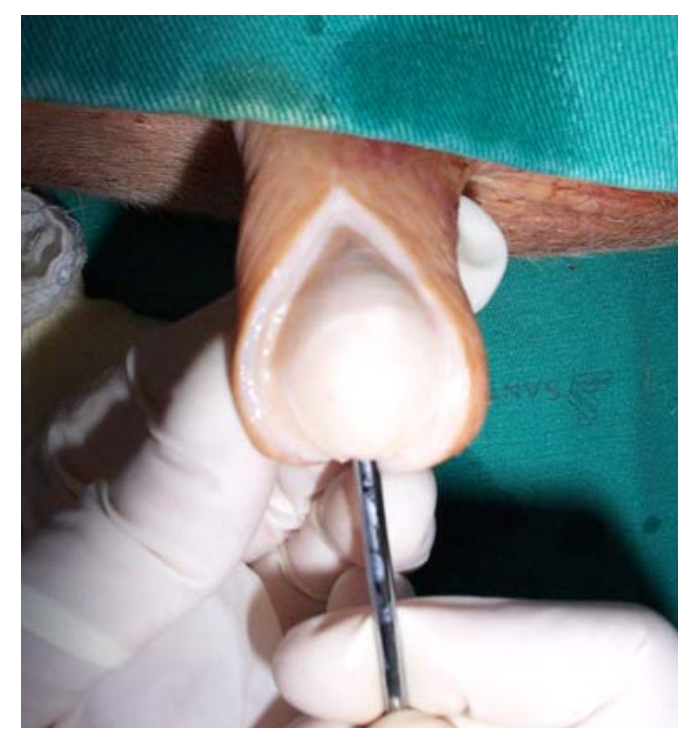

Figura 2. Eversão de mucosa da parte papilar do seio lactífero por rotação de $180^{\circ}$ da sonda mamária.

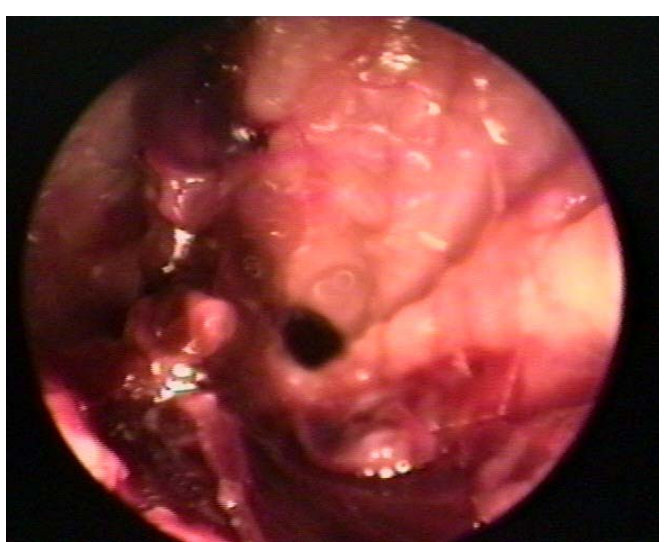

Figura 4. Obstrução luminal da parte papilar do seio lactífero.

Tabela 2. Avaliação videoteloscópica do grau de obstrução (\%) na parte papilar do seio lactífero antes (dia 0) e após (dias 8 e 15) a telotomia lateral e da excisão retangular da mucosa do seio lactífero, com (GCD) ou sem (GSD) a aplicação de dilatadores

\begin{tabular}{|c|c|c|c|c|c|c|c|c|c|c|}
\hline & \multicolumn{5}{|c|}{ GCD } & \multicolumn{5}{|c|}{ GSD } \\
\hline & \multicolumn{5}{|c|}{ Grau de obstrução } & \multicolumn{5}{|c|}{ Grau de obstrução } \\
\hline & $0 \%$ & $25 \%$ & $50 \%$ & $75 \%$ & $100 \%$ & $0 \%$ & $25 \%$ & $50 \%$ & $75 \%$ & $100 \%$ \\
\hline \multirow[t]{2}{*}{ Dia 0} & 100,0 & 0,0 & 0,0 & 0,0 & 0,0 & 0,0 & 0,0 & 0,0 & 0,0 & 0,0 \\
\hline & $(16 / 16)$ & $(0 / 16)$ & $(0 / 16)$ & $(0 / 16)$ & $(0 / 16)$ & $(16 / 16)$ & $(0 / 16)$ & $(0 / 16)$ & $(0 / 16)$ & $(0 / 16)$ \\
\hline \multirow[t]{2}{*}{ Dia 8} & 50,0 & 37,5 & 12,5 & 0,0 & 0,0 & 6,2 & 68,7 & 25,0 & 0,0 & 0,0 \\
\hline & $(8 / 16)$ & $(6 / 16)$ & $(2 / 16)$ & $(0 / 16)$ & $(0 / 16)$ & $(1 / 16)$ & $(11 / 16)$ & $(4 / 16)$ & $(0 / 16)$ & $(0 / 16)$ \\
\hline \multirow[t]{2}{*}{ Dia 15} & 37,5 & 18,7 & 31,2 & 12,5 & 0,0 & 6,2 & 18,7 & 50,0 & 12,5 & 12,5 \\
\hline & $(6 / 16)$ & $(3 / 16)$ & $(5 / 16)$ & $(2 / 16)$ & $(0 / 16)$ & $(1 / 16)$ & $(3 / 16)$ & $(8 / 16)$ & $(2 / 16)$ & $(2 / 16)$ \\
\hline \multirow[t]{2}{*}{ Total } & 62,5 & 18,7 & 14,6 & 4,8 & 0,0 & 37,5 & 29,2 & 25,0 & 4,2 & 4,2 \\
\hline & $(30 / 48)$ & $(9 / 48)$ & $(7 / 48)$ & $(2 / 48)$ & $(0 / 48)$ & $(18 / 48)$ & $(14 / 48)$ & $(12 / 48)$ & $(2 / 48)$ & $(2 / 48)$ \\
\hline
\end{tabular}

Neste estudo, foram registradas ocorrências de cicatrização completa, mucosa não cicatrizada sem invasão do lúmen e lesão de mucosa invasiva. As diferentes ocorrências na cicatrização das incisões lineares diferiram entre os dois grupos (GCD e GSD) e variaram segundo as VT dos dias 8 e 15. 
Quando as ocorrências foram agrupadas, houve evidência de maior freqüência dessas alterações no grupo das papilas que receberam dilatadores $(25 \%$ na VT-8 e 37,5\% na VT-15). No GCD, houve aumento da cicatrização de mucosa do $8^{\circ}$ para o $15^{\circ}$ dia, embora não se tenham detectado diferenças estatísticas. Observou-se, também, uma redução na incidência dessas lesões nas papilas do GSD, entre as duas avaliações, $18,7 \%$ na VT- 8 e $12,5 \%$ na VT15. Por outro lado, a comparação entre grupos, após as VT, mostra aumento de incidência dessas lesões no GCD no $15^{\circ}$ dia $(\mathrm{P} \leq 0,05)$. Pode-se supor, comparativamente, pela divergência dos resultados entre os grupos, que a pressão exercida pelo dilatador sobre a área de mucosa submetida à telorrafia pode predispor a defeitos cicatriciais devido ao afastamento das bordas da ferida, impedindo uma rápida epitelização. Deve-se ressaltar que a adaptação do balonete da sonda de Foley, como dilatador, pela sua forma abaulada, pode ter produzido um aumento de tensão no ponto central da ferida.

A evolução das lesões de mucosa, visualizadas nas VT, que invadiram o lúmen da PPSL não foram consideradas suficientes para obstruir o seio lactífero e foram classificadas conforme descrição contida na Tab. 3 .

Quando os dois grupos foram comparados entre si, por meio das três avaliações videoteloscópicas, observou-se que as lesões induzidas pela excisão retangular da mucosa da PPSL causaram, no GSD, aumento no percentual de alterações $(87,5 \%)$ tanto no $8^{\circ}$ como no $15^{\circ}$ dia $(\mathrm{P} \leq 0,05)$. Estes dados corroboram com a expectativa de Ames e Coy (1984), Modransky e Welker (1993) que preconizam o uso de implantes de tubos de silicone, quando lesões extensas na mucosa da PPSL são provocadas. Dzuba (1983); Nassef et al. (1988) e Tulleners e Hamir (1990) e Metzger et al. (1999) recomendam o uso dos tubos de silicone implantados na PPSL sempre que a lesão na mucosa do seio lactífero não permita boa aposição das bordas da ferida. Consideraram que o implante orienta a cicatrização e impede a granulação excessiva do tecido conjuntivo que leva a obstruções da PPSL (Bristol, 1988). O modelo experimental mostra não haver diferença $(\mathrm{P}<0,05)$ na incidência das alterações após excisão retangular da mucosa no GCD $(43,7 \%$ no dia 8 e $56,2 \%$ no dia 15), mesmo após a retirada dos dilatadores. O aumento do número de papilas com obstrução no GCD, visualizadas entre as duas VT foi pequeno, provavelmente em função do tempo de evolução e, também, pelo fato de as vacas estarem em período seco. Este resultado aponta para o efeito benéfico dos dilatadores na orientação cicatricial e está de acordo com as observações de Trent et al. (1990) que relataram obstrução em todas as papilas mamárias após a retirada dos implantes. Esse relato pode ser reforçado pelos índices elevados de lesões evidenciadas $(87,5 \%)$ na VT-8 e VT-15 no GSD, após a excisão retangular.

A observação da evolução cicatricial na lesão retangular na mucosa da PPSL, por meio das VT nos dias 8 e 15, evidenciaram as seguintes ocorrências: reparação plena da mucosa, invasão do lúmen do seio lactífero e obstrução total do lúmen da papila mamária por tecido granulomatoso. A evolução dessas alterações cicatriciais diferiu entre os dois grupos GCD $(43,7 \%$ no dia 8 e $56,2 \%$ no dia 15$)$ e GSD (87,5\% nos dias 8 e 15$)$.

As VT demonstraram que, ao contrário das lesões lineares provocadas pelas telotomias, houve proliferação intensa de tecido conjuntivo no local onde a mucosa foi excisada, provocando obstruções no lúmen da PPSL em variados graus (Fig. 5). Estes achados concordam com as observações de Ducharme (1987) ao relatar que o grau de obstrução pode variar segundo o procedimento cirúrgico.

O ducto papilar e a deposição de queratina no seu lúmen associada a proteínas catiônicas formam a primeira barreira de defesa da glândula mamária contra infecções. $\mathrm{O}$ formato externo do óstio papilar pode variar e favorecer a permanência de material contaminado por bactérias causadoras de mamites (Apleman, 1973). A roseta de Fürstenberg, região limítrofe entre o ducto papilar e a PPSL, recebe um fluxo sanguíneo quatro vezes maior que os tecidos adjacentes (Jankus e Baumann, 1986), ao favorecer a renovação celular que forma o selo de queratina e ao promover intensa migração de polimorfonucleares para o combate de bactérias que passam pelo ducto papilar. Nickerson (1983), Paape (1991) e Bramley (1998) consideram a roseta de Fürstenberg como a segunda linha de defesa a infecções da glândula mamária. Notou-se, neste estudo, que a permanência dos dilatadores na PPSL, por uma semana, provocou $100 \%$ de insuficiência funcional temporária do ducto papilar. A dilatação provocada pela sonda de Foley, no diâmetro do ducto, segundo McDonald (1975), favorece a ocorrência de afecções ascendentes. O lúmen do ducto papilar apresenta pregas longitudinais, é bastante reduzido (Godinho et al, 
2001), e controlado por um sistema músculoelástico integrado (Van der Merwe, 1985). A retirada da sonda de Foley, usada como dilatador, causou insuficiência do ducto papilar por 8 horas em média, o que favoreceu ao maior índice de mamites. Embora a histologia não tenha mostrado lesões teciduais devido à permanência da sonda de Foley por sete dias, em ambos os grupos foram observadas ocorrências de ductos normais com queratina no lúmen $(62,5 \%$ no GSD e 56,2\% no GCD). Foi apontado, porém, um maior percentual de ductos sem queratina, com processos de epitelização sem focos inflamatórios ou de processo inflamatório difuso com destruição do epitélio de revestimento no GCD, muito provavelmente induzidos pela presença da sonda.

Tabela 3. Distribuição percentual da evolução das lesões induzidas na mucosa da parte papilar do seio lactífero, oito e 15 dias após a telotomia lateral, com (GCD) ou sem (GSD) a aplicação de dilatadores, segundo a avaliação videoteloscópica

\begin{tabular}{ccccccc}
\hline & \multicolumn{3}{c}{ GCD } & \multicolumn{3}{c}{ GSD } \\
\cline { 2 - 7 } & Cicatrizado & $\begin{array}{c}\text { Lesão da } \\
\text { mucosa }\end{array}$ & $\begin{array}{c}\text { Lesão de } \\
\text { mucosa } \\
\text { invasiva }\end{array}$ & Cicatrizado & $\begin{array}{c}\text { Lesão da } \\
\text { mucosa }\end{array}$ & $\begin{array}{c}\text { Lesão de } \\
\text { mucosa } \\
\text { invasiva }\end{array}$ \\
\hline Dia 0 & 0,0 & 0,0 & 0,0 & 0,0 & 0,0 & 0,0 \\
Dia 8 & 75,0 & 18,7 & 6,2 & 81,2 & 18,7 & 0,0 \\
Dia 15 & 62,5 & 6,2 & 31,2 & 87,5 & 12,5 & 0,0 \\
Total & $79,2(38 / 48)$ & $8,3(4 / 48)$ & $12,5(6 / 48)$ & $89,6(43 / 48)$ & $10,4(5 / 48)$ & $0(0 / 48)$ \\
\hline
\end{tabular}

Foram evidenciadas deiscências no GCD, em $18,7 \%$ na VT do dia 8 e em $12,5 \%$ na VT do dia 15. Isso pode ser justificado pelo fato de o balonete da sonda de Foley, quando insuflado, ter exercido maior pressão sobre a linha de sutura da telotomia. Os resultados encontrados estão de acordo com Tulleners e Hamir (1990) que observaram maior tendência de deiscência em telotomias nas quais foram aplicados implantes de tubos de silicone na PPSL. Arighi (1987), Nassef et al. (1988) e Metzger (1999) observaram várias complicações decorrentes do uso de implantes, tais como, mamites, metaplasias epiteliais e infiltração de polimorfonucleares, que são reações típicas à presença de corpo estranho na PPSL.

A dilatação da PPSL pelo balonete da sonda de Foley, utilizado neste experimento, ocasionou um menor índice de obstruções e, pela análise histológica dos cortes transversais da PPSL, foram observadas alterações distribuídas sem tendência percentual entre os grupos. Metaplasia epitelial ocorreu em um seio lactífero do GCD, alteração que também foi observada por Nassef et al. (1988), porém em maior freqüência. Os variados graus de metaplasia e hiperplasia epitelial foram observados em estudos onde os tubos de silicone permaneceram implantados por pelo menos uma lactação completa (Nassef et al., 1988) ou em períodos de dois meses (Tulleners e Hamir, 1990). No presente estudo, a curta permanência das sondas, em relação aos trabalhos acima citados, tem relação direta com os menores índices de metaplasia epitelial na PPSL.
As proliferações teciduais ocorridas foram mais intensas e invasivas no seio lactífero das papilas do GSD, onde o tecido conjuntivo frouxo não teve a contenção do dilatador por sete dias produzindo maior ocorrência de obstruções. Por outro lado, a presença dos dilatadores na PPSL provocou maior índice de alterações histológicas na mucosa papilar, ocorreram $87,5 \%$ de alterações histológicas no GCD e $68,75 \%$ no GSD. Este resultado concorda com as observações de Nickerson et al. (1987), que indicam a presença de corpos estranhos na PPSL causa das reações no epitélio de revestimento e do aumento do fluxo de polimorfonucleares para essa região.

Nos dois grupos foram observadas, nas VT-8 e VT15, presença de bridas (Fig. 6), com maior incidência no GSD devido à proximidade das lesões lineares e retangulares na PPSL. Os procedimentos videoteloscópicos são recomendados para reduzir bridas, impedindo a evolução para um processo obstrutivo mais grave (Medl, 1994; John et. al, 1998; Hirsbrunner e Steiner, 1999), como comprovam estudos que comparam a utilização de técnicas cirúrgicas, tradicionais e teloscópicas. A técnica cirúrgica telescópica confere ótima ação investigativa e precocidade nas condutas (Isumizawa et al, 1995; Shakespeare, 1988; Geihauser e Querengasser, 2000). Considera-se também a imediata ação terapêutica, que traz melhorias substanciais na resolução das afecções das papilas mamárias (Hirsbrunner, 2001). 


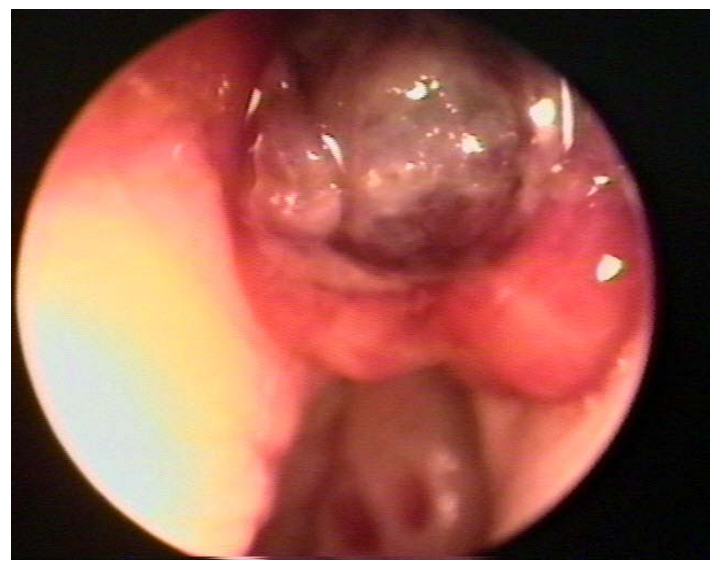

Figura 5. Proliferação de tecido conjuntivo na região do defeito retangular, invadindo a parte papilar do seio lactífero.

\section{CONCLUSÕES}

O uso temporário de dilatador na parte papilar do seio lactífero orienta a cicatrização da excisão retangular, permitindo a manutenção da patência do seio lactífero, embora cause alterações no revestimento epitelial favorecendo infecções na papila mamária. A avaliação videoteloscópica das lesões provocadas na mucosa da parte papilar do seio lactífero permite acompanhar a evolução da reparação cicatricial das lesões.

\section{AGRADECIMENTO}

À FAPEMIG pelo apoio na aquisição do videotelescópio e publicação.

\section{REFERÊNCIAS BIBLIOGRÁFICAS}

AGGER, J.F.; HESSELHOLT, M. Epidemiology of teat lesions in a dairy herd. I: description of incidence, location and clinical appearance. Nord. Vetmed., v.38, p.209-219, 1986.

AGGER, J.F.; WILLEBERG, P. Epidemiology of teat lesions in a dairy herd. II: description of incidence, location and clinical appearance. Nord. Vetmed., v.38, p.220-232, 1986.

AMES, N.K.; COY, C.H. Placement of drain tubes in obstructed teats. Mod. Vet. Pract., v.60, p.775-777, 1984.

APPLEMAN, R.D. Subjective evaluation of teat canal anatomy. J. Dairy Sci., v.56, p.411-413, 1973.

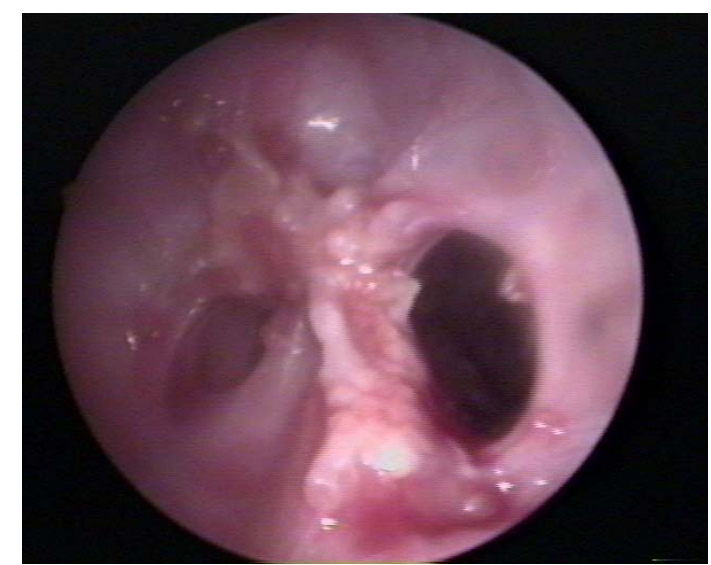

Figura 6. Brida tissular com união do defeito retangular ao defeito linear.

BRAMLEY, A.J. Mastitis: phisiology or pathology? Flemish Vet. J., v.62, suppl. 1, p.311, 1991 .

BRISTOL, D.G. Treatment of teat obstruction in a cow by transfer oral mucosa and temporary implantation of an intraluminal tube. J. Am. Vet. Assoc., v.195, p.492-4, 1988.

DZUBA, L.M. Reconstructive test surgery for complete teat canal obstructions. Bovine Pract., v.13, p.208-211, 1983.

FERREIRA, H. I. Fibrose obstrutiva da papila mamária em vacas. Estudo clínico, radiológico, da técnica operatória e histológico. 1973. 69f. Dissertação (Mestrado) - Escola de Veterinária, Universidade Federal de Minas Gerais, Belo Horizonte.

GODINHO, H.P.; CARDOSO, F.M.; NASCIMENTO, J.F. (Eds). Anatomia dos ruminantes domésticos. Belo Horizonte: UFMG, 2003. 386p.

HAMANN, J.; MEIN, G.A.; WETZEL, S. Teat tissue reactions to milking: effects of vacuum level. J. Dairy Sci., v.76, p.1040-1046, 1993.

HULL ,B.L. Teat and udder surgery. Vet. Clin. N. Am., v.11, p.1-17. 1995.

HUSTON, G.E.; HEALD, C.W. Effect of the intramamary device on milk infection status, yield and somatic count and the morphological features of the lactiferous sinus of the bovine udder. Am. J. Vet. Res., v.44, p.1856-1860, 1983.

JANKUS, E.F.; BAUMANN, L.E. Blood flow to the distal part of the teat (mammary papilla) of 
lactating dairy cows. Am. J. Vet. Res., v.47, p.283-285, 1986.

JOHN, H.; HÄSSIG, M.; GOBET, D. et al. A new operative method to treat high stenoses in dairy cows. Br. J. Urol., v.82, p.906-909, 1998.

McDONALD, J.S. Radiographic method for anatomic study of the teat canal: characteristics related to resistance to new intramammary infection during lactation and early dry period. Cornell Vet., v.65, p.492-499, 1975.

METZGER, L.; HIRSBRUNENER, G.; WALDVOGEL, A. et al. Permanent implantation of a reinforced plytetrafluoroethylene vascular graft for treatment of artificial defects of the teat cistern mucosa in cows. Am. J. Vet. Res., v.60, p.56-62, 1999.

MODRANSKY, P.; WELKER, B. Diagnosing and treating milk flow problems. Vet. Med., v.88, p.788804, 1993.

NASSEF, M.T.; COY, C.H.; WATSON, G.L. Method to create and maintain the patency of the bovine mammary papilla. Am. J. Vet. Res., v.49, p.1131-1133, 1988.
NICKEL, R.; SCHUMMER, A.; SEIFERLE, E. et al. The circulatory system, the skin, and the cutaneous organs of the domestic mammals. In: SCHUMMER, A. (Ed). The anatomy of the domestic animal. Berlin: Verlag Paul Parey, 1981. p.11-508.

NICKERSON, S.C.; THOMPSON, W.J.; KORTUM, W.M. et al. Histological response of bovine mammary tissue to an intracisternal bead device. J. Dairy Sci., v.70, p.687-695, 1987.

PAAPE, M.J.; WERGIN, W.P.; GUIDRY, A.J. et al.. Leukocytic defense mechanisms in the udder. Flemish Vet. J., v.62, suppl. 1, p.95-109, 1991.

ROINE, K. Observations on teat stenosis. Nord. Vet.-Med., v.27, p.107-111, 1975.

TULLENERS, E.; HAMIR, A. Effects of teat cistern mural biopsy and teatoscopy stab versus longitudinal incision with or without tube implant on incisional healing in lactating dairy cattle. Am. J. Vet. Res., v.51, p.1257-1266, 1990.

VAN DER MERWE, N.J. Some observations on the morphology of the bovine teat canal (Ductus papillaris mammae). J. S. Afr. Vet. Assoc., v.56, p.13-16, 1985. 